\title{
Influence of Different Levels of Adsorbent "Vitacorm Reo-M" on the Morphological and Biochemical Blood Parameters of the Gilts
}

\author{
Busev Vitali, Caisin Larisa
}

\author{
Department of Animal Science, State Agrarian University of Moldova, Chisinau
}

\begin{abstract}
The study was carried out to determine the effects of levels of adsorbent "Vitacorm REO-M" on the growth, hematology, and serum biochemistry of pigs. The pigs were separated into four groups and further randomized design and fed diets contained by weight: concentrates grain mixture consisting of barley $-43.0 \%$, corn $-10.0 \%$, wheat $-11.0-11.5 \%$, peas $-8.0-8.5 \%$, and also bran - 6.0-8.0\%, soybean meal - 5.0-9.0\%, sunflower meal $-6.0 \%$, fish meal $-5.0 \%$, soybean oil $2.0 \%$, premix $-2.5 \%$. The control animals $(C G)$ were fed the main diet and $E G_{1}, E G_{2}$ and EG3 diet included adsorbent additive "Vitacorm REO-M" in the amount of $2.0,4.0$ and $6.0 \mathrm{~kg}$ per ton offeed, respectively. The pigs were adequately housed, while feed and potable water were supplied ad libitum. At the end of the experiment 3 pigs were randomly sampled from each treatment ( 1 per replicate) and blood collected through venipuncture on veins at backside of the ears. Results showed significant $(P \leq 0.05)$ effect of "Vitacorm REO-M" at a dosage of $4 \mathrm{~kg}$ per ton offeed allowed to obtain an additional average daily gain in $E G_{2}(0.541 \mathrm{~kg}) 7.98 \%$ higher than in the CG. Was found that the highest content of total protein at the end of the experience was observed in CG-68.95\% (while in $E G_{2}-64.43 \%, E G_{1}-64.62 \%, E G_{3}-63.22 \%$ ) and the highest level of $\gamma$-globulin content was noted in $E G_{1}$ and $E G_{3}$, respectively 9.33 and $9.53 \%$. AST activity maximum increase (at a rate of 22.0-47.0 u/l) was observed in animals of the $E G_{1}$ by $11.11 \%$, and a decrease of $7.02 \%$ in $E G_{3}$ relative to the $C G$. In the $E G_{2}$, the AST index was within the normal range - $40.0 \mathrm{U} / \mathrm{l}$. $A L T$ activity was reduced in comparison with the CG in the $E G_{1}$ by $4.23 \%-3.0 \mathrm{U} / \mathrm{l}$, in the $E G_{2}-$ by $19.72 \%-14.0$ $U / l$.
\end{abstract}

Keywords- adsorbent, blood parameters, growth performance, pigs.

\section{INTRODUCTION}

Mycotoxins are toxic metabolites produced by several fungi species, with the aflatoxins, fumonisins, zearalenone, trichothecenes and ochratoxin A being the most important found in feedstuffs. The contamination of feed with mycotoxins is a continuing feed safety issue leading to economic losses in animal production [1]. The economic impact of mycotoxins includes mortality of domestic animals, increased costs due to veterinary care and decreased production efficiency, especially in poultry and swine operations [2]. Mycotoxin control is essential for health and performance, as mycotoxins contaminate almost all agricultural ingredients. A mycotoxin survey on different feedstuffs in specific areas allows the correct implementation of cost-effective control programs. Reducing the bioavailability of mycotoxins is aimed at reducing toxic effects due to the inclusion of toxic pollutants in various binders or sorbents. This approach allows preventing the harmful effects of various mycotoxins on animal organisms (primarily poultry and pigs) by reducing the degree of absorption and subsequent distribution by blood. Detoxification methods should also be affordable and easy to use. The optimal solution to the mycotoxicosis problem is the use of supplements in diets that, when introduced into feed, become active against mycotoxins directly in the animal's body. Practical methods to detoxify mycotoxin contaminated grain on a large scale and in a cost-effective manner are not currently available. A current approach is to add nonnutritive feed additives, such as sorptive materials, to the diet in order to reduce the absorption of mycotoxins in the gastrointestinal tract $[3,4]$.

\section{MATERIAL AND METHODS}

\subsection{Experimental design, animals and diets}

The experimental part of the research was implemented by conducting scientific and business experience, accompanied by a series of laboratory analyzes. In the scientific and business experience in the conditions of the State Enterprise for the Selection and Hybridization of Pigs "Moldsuingibrid" Orhei District), the effectiveness of the use of the adsorbent additive Vitacorm REO-M in the compound feeds of young pigs was studied. Experimental design, animals and diets 150-day study with a total of 40 cross bred pigs [the same genotype] with an initial body weight (BW) of $17.8-17.9 \mathrm{~kg}$ were 
randomly assigned to 4 dietary treatments (10 pigs in each) for in vivo experiments.

The feeding and caring conditions of the experimental pigs were the same; they were fed compound feeds prepared from local feeds in accordance with detailed feeding norms [10]. The basal diet contained by weight: concentrates: grain mixture consisting of barley $-43.0 \%$, corn $-10.0 \%$, wheat $-11.0-11.5 \%$, peas $-8.0-8.5 \%$, and also bran - 6.0-8.0\%, soybean meal - 5.0-9.0\%, sunflower meal $-6.0 \%$, fish meal $-5.0 \%$, soybean oil $2.0 \%$, premix $-2.5 \%$. The control animals were fed the main diet without the addition of the adsorbent. The composition of feed for $\mathrm{EG}_{1}, \mathrm{EG}_{2}$ and $\mathrm{EG}_{3}$ included adsorbent additive "Vitacorm REO-M" in the amount of $2.0,4.0$ and $6.0 \mathrm{~kg}$ per ton of feed, respectively. The tested preparations of adsorbents in the composition of these feeds were injected using standard dispensers, which contributed to their more uniform mixing with other ingredients.

The main task of the scientific research was to identify the most effective levels of adsorbent injection and their effect on the hematological parameters of growing pigs, as well as the development of new ways to increase the efficiency of the use of mycotoxin-adsorbing supplements.

The experiment used the adsorbent "Vitacorm REO-M" feed additive-sorbent-re-modifier used for the prevention of toxicosis in farm animals and poultry when feeding feeds affected by mycotoxins, as well as in order to obtain environmentally friendly products. "Vitacorm REO-M" contains extruded wheat seeding - $10 \%$, bentonite $-25 \%$, vermiculite $-25 \%$, palygorskite clay - 30\%, acidifier at least - 5\%, yeast autolysate - 5\%, which normalizes metabolism, improves feed conversion.

At the beginning of the experiments and at the end of each period, the animals were weighed in order to study the dynamics of general and average daily gains. The absolute increase in live weight by periods of cultivation is calculated by the formula:

$$
\boldsymbol{A}=\boldsymbol{W} \boldsymbol{t}-\boldsymbol{W}_{\boldsymbol{0}}, \text { where: }
$$

Table.1: The indicators of body weight of the pigs during the period of experiment, $k g\left(\bar{X}_{ \pm} \bar{S}_{\overline{\mathrm{x}}}\right)$

\begin{tabular}{|c|c|c|c|c|}
\hline Indicators & CG & $\mathbf{E G}$ & $\mathbf{E G}_{2}$ & $\mathbf{E G}_{3}$ \\
\hline At the beginning of the preparatory stage of the experiment & $17.9 \pm 0.169$ & $17.8 \pm 0.189$ & $17.8 \pm 0.155$ & $17.9 \pm 0.145$ \\
\hline At the beginning of the experiment & $18.7 \pm 0.174$ & $18.5 \pm 0.206$ & $18.6 \pm 0.176$ & $18.8 \pm 0.148$ \\
\hline At the end of the I stage of the experiment & $29.8 \pm 0.588$ & $29.7 \pm 0.206$ & $31.0 \pm 0.533$ & $30.8 \pm 0.654$ \\
\hline At the end of the II stage of the experiment & $42.3 \pm 1.57$ & $44.5 \pm 1.81$ & $46.1 \pm 1.19^{*}$ & $45.9 \pm 0.68^{*}$ \\
\hline At the end of the experiment & $94.3 \pm 1.96$ & $96.6 \pm 2.38$ & $100.0 \pm 1.32 * *$ & $96.7 \pm 1.72$ \\
\hline - in \% compared to the control & 100.00 & 102.49 & 106.31 & 102.51 \\
\hline \multicolumn{5}{|l|}{ The increase in body weight for the experiment: } \\
\hline - absolute, $\mathrm{kg}$ & $75.6 \pm 1.86$ & $78.1 \pm 2.32$ & $81.6 \pm 1.36$ & $77.8 \pm 1.69$ \\
\hline - in $\%$ compared to the control & 100.00 & 103.32 & 107.94 & 102.92 \\
\hline
\end{tabular}




\section{RESULTS AND DISSCUSSION}

\subsection{Growth performance and blood analyses}

In general, during the experience, the best indicators in live weight were obtained in $\mathrm{EG}_{2}$, in pigs that received $4 \mathrm{~kg}$ of the adsorbent additive "Vitacorm REO-M" per ton of feed; the animals in this group reached a mass of $100.28 \mathrm{~kg}$, which is $6.31 \%$ more, than in CG $(94.33 \mathrm{~kg})$. In the other two experimental groups, a higher growth in live weight in $\mathrm{EG}_{1}-96.68 \mathrm{~kg}$ was also observed, which is higher compared to the control group by $2.49 \%$, and in $\mathrm{EG}_{3}-96.7 \mathrm{~kg}$, which is $2.51 \%$ more, respectively. The indicators of animal productivity over the study period are presented in Table Error! Not a valid bookmark self-reference..

Table.2: Average daily gain of pigs by stages of experiment, $\mathrm{kg}(\bar{X} \pm \overline{\mathrm{x}})$

\begin{tabular}{|l|l|l|l|l|}
\hline Stages of the experience & $\mathbf{C G}$ & $\mathbf{E G}_{1}$ & $\mathbf{E G}_{2}$ & $\mathbf{E G}_{\mathbf{3}}$ \\
\hline $\begin{array}{l}\text { At the preparatory stage of the } \\
\text { experiment }\end{array}$ & $0.089 \pm 0.003$ & $0.080 \pm 0.004$ & $0.090 \pm 0.006$ & $0.094 \pm 0.003$ \\
\hline At the I stage of the experiment & $0.409 \pm 0.026$ & $0.448 \pm 0.030$ & $0.475 \pm 0.020^{*}$ & $0.466 \pm 0.011^{*}$ \\
\hline At the II stage of the experiment & $0.559 \pm 0.017$ & $0.562 \pm 0.021$ & $0.582 \pm 0,019$ & $0.547 \pm 0.021$ \\
\hline The whole experiment & $0.501 \pm 0.012$ & $0.518 \pm 0.015$ & $0.541 \pm 0.009^{*} *$ & $0.516 \pm 0.011$ \\
\hline
\end{tabular}

$* \mathrm{p} \leq 0.1 ; * * \mathrm{p} \leq 0.05$

Adsorbent additive "Vitacorm REO-M" at a dosage of 4 $\mathrm{kg}$ per ton of feed allowed to obtain an additional average daily gain in $\mathrm{EG}_{2}(0.541 \mathrm{~kg}) 7.98 \%$ higher than in the $\mathrm{CG}$, this indicator was the best both in growing periods and in general for the experience. The pigs from $\mathrm{EG}_{1}$ and $\mathrm{EG}_{3}$ showed an average daily gain of 0.518 and $0.516 \mathrm{~kg}$, respectively, which is 3.39 and $2.99 \%$ higher than in the CG.

The blood indices of the experimental pigs were studied in order to study the effect of different input levels of the adsorbent additive Vitacorm PEO-M on the body of the pigs. At the beginning (06.06.2012) and at the end (05.11.2012) of the experiment, blood samples were taken for subsequent analysis of the biochemical and morphological parameters in the laboratory. Blood samples for analysis were taken from three pigs from each group (Figure 1).

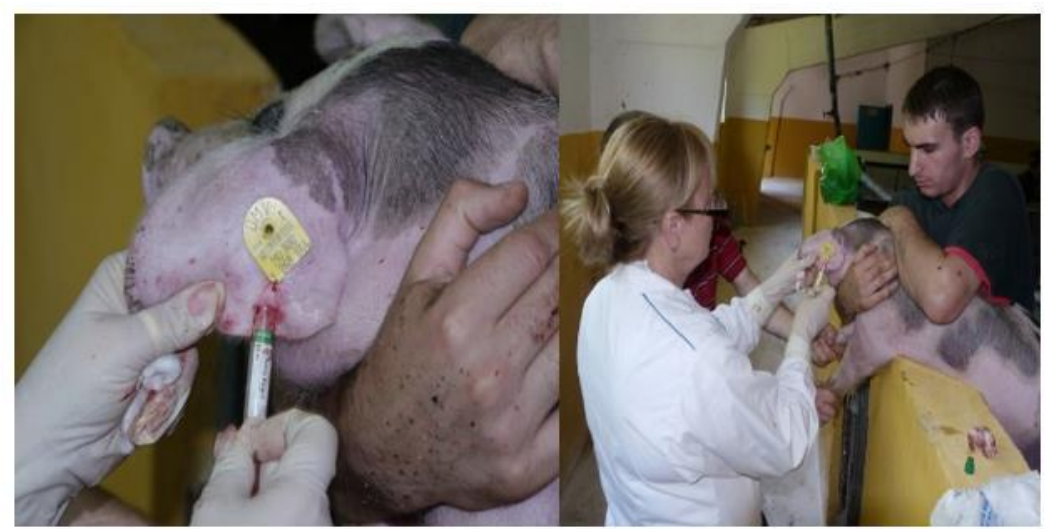

Fig. 1. Blood sampling

The analysis of the hematological profile parameters showed that according to the results obtained after statistical processing of the data on the number of erythrocytes, hemoglobin, leukocytes, total protein in the blood, as well as the content of calcium, phosphorus and protein fractions in blood serum, the physiological reactivity of the animals in all groups at the beginning of the experience was the same. One of the most important cellular elements of the blood are red blood cells, which are spongy little bodies, whose small pores are filled with hemoglobin, the very substance that helps red blood cells to perform the function of transporting gases. Red blood cells make up the bulk of the blood cells. In our study, the number of erythrocytes in the animals of all experimental groups naturally increased and was higher than in the control group by $1.33-3.19 \%$ (figure 2). 


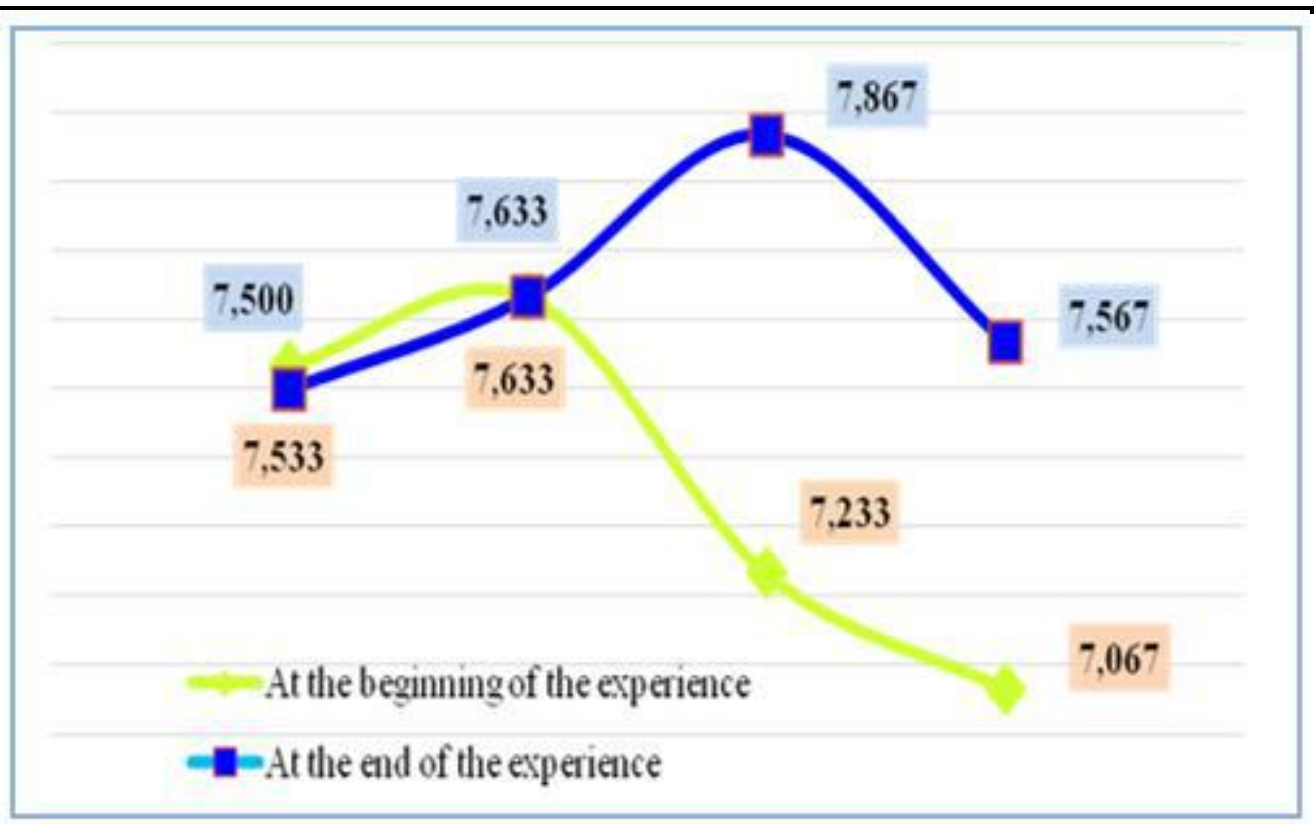

Fig. 2. The content of red blood cells in pigs, $10^{12} / l$

It is known that with age in the blood of animals there is a tendency of increasing the number of erythrocytes and leukocytes, while reducing the hemoglobin content, reducing the color index, but the number of blood platelets remains almost unchanged. Consequently, hemoleukopoesis in 6-7-month-old animals slightly increases, which can be associated with high growth energy of the individuals of this age. The number of leukocytes in the experimental groups $\mathrm{EG}_{1}, \mathrm{EG}_{2}$ and $\mathrm{EG}_{3}$ under the influence of the adsorbent inclusion was higher in comparison with the control animals by $0.660,0.133$ and $2.77 * 10^{9} / 1$, respectively (Table 3 ), which indirectly characterizes the degree of resistance of the body.

Even greater differences in data are found for hemoglobin. The hemoglobin content in pigs is $100-120$ grams per liter of blood. In the experiment it was better expressed in the control group, the gilts of the first experimental group were inferior to them by $8.33 \mathrm{~g} / 1$ $(\mathrm{p} \leq 0.05)$. For a more significant amount in favor of the control group, the data differed in pigs of the second group, in whose blood the hemoglobin content was $11.33 \mathrm{~g} / 1$ lower $(\mathrm{p} \leq 0.1)$ (Table 3). The hemoglobin in the blood is a protein that participates in the process of transporting oxygen from the lungs to the tissues and organs of the body. In the capillaries of the lungs, oxygen combines with hemoglobin and, along with the blood stream, spreads through the body, along the way getting rid of the compound with protein and joining other substances. At the same time, carbon dioxide is added to the hemoglobin, which must be removed from the tissues.

Table.IV: The morphological parameters of the blood of the pigs at the end of experiment, $\bar{X} \pm S \overline{\mathrm{x}}$

\begin{tabular}{|l|l|l|l|l|}
\hline Hemoglobin, $\mathbf{g} / \mathbf{l}$ & $\mathbf{1 2 9 . 3 3} \pm \mathbf{1 . 4 5 3}$ & $\mathbf{1 2 1 . 0 0} \pm \mathbf{1 . 0 0 0} * *$ & $\mathbf{1 1 8 . 0 0} \pm \mathbf{3 . 6 0 6} *$ & $\mathbf{1 2 1 . 3 3} \pm \mathbf{5 . 7 8 3}$ \\
\hline Leukocytes, $\mathbf{1 0} \boldsymbol{9} / \mathbf{l}$ & $21.13 \pm 2.085$ & $21.79 \pm 0.806$ & $21.26 \pm 2.326$ & $23.90 \pm 1.100$ \\
\hline Color indicator, units & $0.497 \pm 0.009$ & $0.500 \pm 0.021$ & $0.470 \pm 0.010$ & $0.503 \pm 0.012$ \\
\hline Lymphocytes, $\mathbf{1 0} \boldsymbol{9} / \mathbf{l}$ & $58.33 \pm 6.766$ & $67.67 \pm 4.667$ & $71.33 \pm 4.667$ & $57.00 \pm 4.583$ \\
\hline
\end{tabular}

$* \mathrm{p} \leq 0.1 ; * * \mathrm{p} \leq 0.05$

The most important components of blood are also nitrogenous compounds, where the proteins take the most important part in the metabolism [12]. Blood serum proteins are divided into several fractions according to a number of physiological functions. They play an important role in the body's defensive activity, water metabolism, transportation of nutrients, metabolic products, and blood coagulation. Proteins are the most important biologically active substances, and their level in the blood to a certain extent determines the indicator of the intensity of protein metabolism in the body [13, 14].

Unspecified dynamics of the protein spectrum is noted in the blood of the pigs when using the additives of an adsorbent preparation.

According to the results of the obtained analyzes, we have found that the total protein content in the blood of the experimental pigs of all groups at the end of the experience was significantly higher than at the beginning 
of the experience. Moreover, the highest content of total protein at the end of the experience was observed in $\mathrm{CG}$ $68.95 \%$, while in $\mathrm{EG}_{2}-64.43 \%, \mathrm{EG}_{1}-64.62 \%, \mathrm{EG}_{3}-$ $63.22 \%$ (Table 4). The revealed changes in the protein spectrum of the young pigs from the experimental groups are associated with age-related features, intensive protein metabolism, which ensures enhanced growth of their body, which is confirmed by higher average daily gains of the piglets [15].

Table.4: The content of protein and its fractions in the blood of pigs at the beginning and at the end of the experiment, $\bar{X} \pm S \overline{\mathrm{x}}$

\begin{tabular}{|l|c|c|c|c|}
\hline \multirow{2}{*}{ Indicators } & \multicolumn{4}{|c|}{ Groups } \\
\cline { 2 - 5 } & CG & \multicolumn{3}{|c|}{ At the beginning of the experiment } \\
\hline \multicolumn{5}{|c|}{ EG $_{2}$} \\
\hline Total protein, g/l & $48.58 \pm 3.239$ & $45.98 \pm 8.660$ & $48.73 \pm 1.681$ & $53.50 \pm 1.202$ \\
\hline Albumins, g/l & $29.29 \pm 2.829$ & $30.22 \pm 1.896$ & $26.37 \pm 3.439$ & $27.12 \pm 2.264$ \\
\hline Albumins, \% & $34.80 \pm 3.121$ & $34.23 \pm 6.293$ & $37.73 \pm 5.716$ & $37.67 \pm 2.972$ \\
\hline$\alpha_{1}$-globulins, \% & $10.10 \pm 4.245$ & $4.20 \pm 0.781$ & $4.24 \pm 0.504$ & $4.20 \pm 0.200$ \\
\hline$\alpha_{2}$-globulins, \% & $31.63 \pm 2.842$ & $26.60 \pm 4.951$ & $36.83 \pm 4.043$ & $34.30 \pm 1.557$ \\
\hline$\beta_{1}$-globulins, \% & $12.37 \pm 2.095$ & $23.40 \pm 10.982$ & $12.53 \pm 0.418$ & $13.30 \pm 0.700$ \\
\hline$\gamma$-globulins, \% & $11.10 \pm 0.833$ & $11.57 \pm 1.384$ & $8.67 \pm 1.746$ & $10.53 \pm 0.797$ \\
\hline A / G - coefficient & $0.54 \pm 0.076$ & $0.55 \pm 0.141$ & $0.63 \pm 0.139$ & $0.61 \pm 0.074$ \\
\hline \multicolumn{5}{|c|}{ At the end of the experiment } \\
\hline Total protein, g/l & $68.95 \pm 1.133$ & $64.62 \pm 0.518 * *$ & $64.43 \pm 1.494 *$ & $63.22 \pm 0.747 * *$ \\
\hline Albumins, g/1 & $33.63 \pm 0.412$ & $32.18 \pm 0.181 *$ & $32.92 \pm 1.109$ & $32.10 \pm 2.987$ \\
\hline Albumins, \% & $38.33 \pm 0.657$ & $37.50 \pm 2.255$ & $40.43 \pm 1.517$ & $39.10 \pm 0.755$ \\
\hline$\alpha_{1}$-globulins, \% & $2.50 \pm 0.265$ & $2.47 \pm 0.033$ & $2.30 \pm 0.100$ & $2.60 \pm 0.100$ \\
\hline$\alpha_{2}$-globulins, \% & $22.37 \pm 1.576$ & $22.60 \pm 0.416$ & $23.73 \pm 1.087$ & $23.14 \pm 1.017$ \\
\hline$\beta_{1}$-globulins, \% & $17.47 \pm 0.481$ & $18.50 \pm 0.700$ & $17.67 \pm 1.157$ & $16.03 \pm 1.267$ \\
\hline$\beta_{2}$-globulins, \% & $10.53 \pm 1.691$ & $9.60 \pm 0.656$ & $7.97 \pm 1.071$ & $9.60 \pm 0.656$ \\
\hline$\gamma$-globulins, \% & $8.80 \pm 0.709$ & $9.33 \pm 1.084$ & $7.90 \pm 0.611$ & $9.53 \pm 1.068$ \\
\hline A / G - coefficient & $0.62 \pm 0.019$ & $0.60 \pm 0.057$ & $0.68 \pm 0.046$ & $0.64 \pm 0.022$ \\
\hline
\end{tabular}

Our data conform to the results of other researchers who report that a lower total protein content in the blood of animals is due to more intensive processes of protein metabolism in their bodies with high growth energy [16, 17].

The state of the natural resistance of animals is studied according to the main indicators of cellular and humoral protection factors - phagocytic, bactericidal, lysozyme activity and serum gamma globulin levels $[18,19,20$, 21].

There is a number of biochemical blood parameters by which one can judge the general condition of the body and the level of metabolic processes in it. Proteins are vital components of plasma. Thus, albumin plays an important role in maintaining osmotic pressure, transport of calcium, tryptophan, bilirubin, bile salts. Alpha and beta globulins transport hormones (thyroxin, insulin), as well as iron and some vitamins. Gamma globulins are involved in the immune response.

An important plastic material which is used as an energy source, if necessary, are albumins, which, forming complexes with toxic substances, neutralize them. Albumin is one of the protein fractions, a decrease in the level of which may indicate liver damage and the presence of infectious processes in the body. According to the results of our biochemical tests, the albumin index in the three groups was within the physiological norm (23$40 \mathrm{~g} / \mathrm{l})$ [22]: in the control group - $33.63 \mathrm{~g} / 1$, in $\mathrm{EG}_{1}$ $32.18 \mathrm{~g} / \mathrm{l}$, in $\mathrm{EG}_{2}-32.92 \mathrm{~g} / \mathrm{l}$ and in $\mathrm{EG}_{3}-32.10 \mathrm{~g} / \mathrm{l}$ (Table 4).

Proteins of globulin fractions, in particular $\alpha$ - and $\beta$ globulins, are actively involved in maintaining the osmotic pressure of the blood. In addition, $\beta$ - globulins actively exhibit protective properties. The immune properties of $\gamma$-globulins are most strongly manifested, since they contain antibodies to the causative agents of various infectious diseases and are the main carriers of antibodies in the body. In the experiment, the highest level of $\gamma$-globulin content was noted in $\mathrm{EG}_{1}$ and $\mathrm{EG}_{3}$, respectively, 9.33 and $9.53 \%$ (Figure 3 ). 


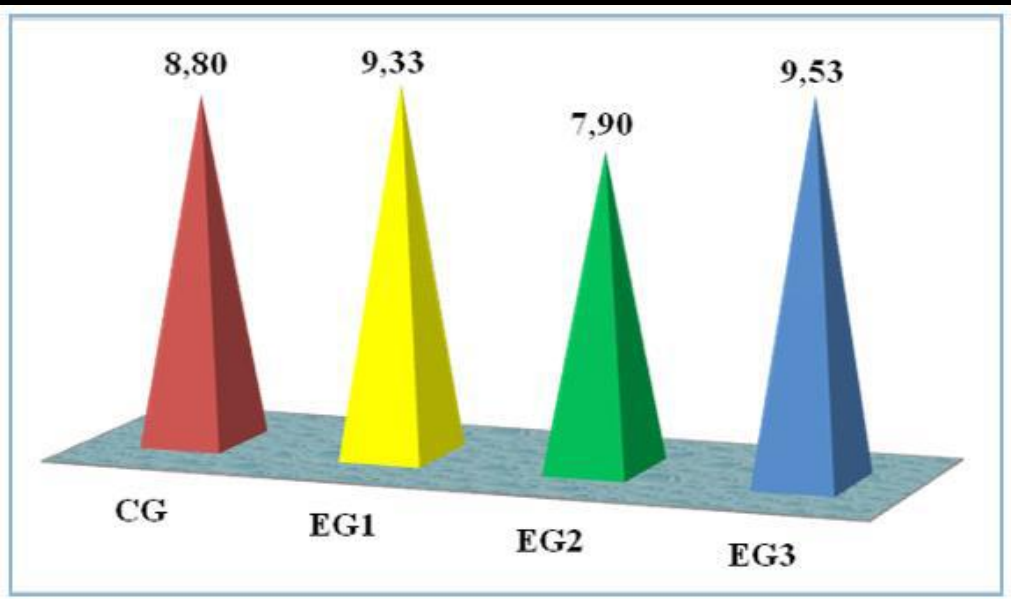

Fig. IV. The content of $\gamma$-globulin in the blood of pigs at the end of the experiment, \%

Metabolism consists of a combination of many chemical reactions that occur in the body. The course of these reactions is carried out with the help of biological catalysts-enzymes, one of which is the class of transferases, which catalyze the hydrolytic cleavage of intramolecular bonds.

An increase in the activity of aspartate aminotransferase (AST) (a key enzyme for the metabolism of nitrogenous substances) and alaninaminotranspherase (ALT) (an enzyme characterizing the use of amino acids in the process of gluconeogenesis) in serum is observed in diseases associated with cell destruction, liver diseases, renal necrosis.

In our studies, the maximum increase in AST activity (at a rate of 22.0-47.0 u / 1) was observed in animals of the first experimental group by $11.11 \%$, and a decrease of $7.02 \%$ in the third experimental group relative to the control group. In the second experimental group, the AST index was within the normal range $-40.0 \mathrm{u} / \mathrm{l}$. ALT activity was reduced in comparison with the control group in the first experimental group by $4.23 \%-3.0$ units / 1 , in the second experimental group - by $19.72 \%$ - 14.0 units / 1 (Figure 4).

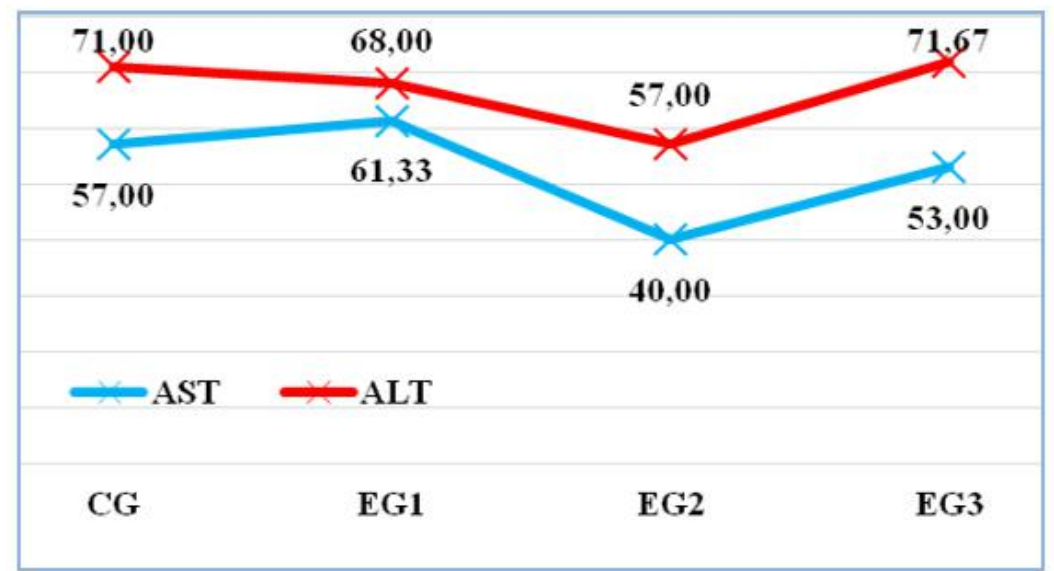

Fig. 4. AST and ALT content in the blood of pigs at the end at the experiment, U/l

The introduction of different doses of the adsorbent to the basic ration did not have a significant effect on the mineral composition of blood in comparison with the control group. A slight decrease in the blood content of piglets from the experimental groups of calcium and phosphorus indicates the presence of hidden processes in the body, associated with exposure to external conditions — insufficient ventilation and high air temperature, low bioavailability of feed nutrients, etc.

In general, all blood parameters of the experimental animals did not exceed the physiological norms. This suggests that the adsorbent additive "Vitacorm REO-M" does not have an allergic or other negative effect on the animal's body and especially it helps to improve the mineral metabolism in it. Consequently, judging by the results of blood tests of the experimental animals, the studied doses of adsorbents in the composition of their diets do not reduce the level of internal constancy of the body. 


\section{CONCLUSION}

Hematological tests belong to important laboratory diagnostic methods. Blood composition and proportion of the components are important indicators of health and functional status of the organism. Adsorbent additive "Vitacorm REO-M" at a dosage of $4 \mathrm{~kg}$ per ton of feed allowed to obtain an additional average daily gain in $\mathrm{EG}_{2}$ $(0.541 \mathrm{~kg}) 7.98 \%$ higher than in the CG.

The number of erythrocytes in the animals of all experimental groups naturally increased and was higher than in the control group by $1.33-3.19 \%$. The number of leukocytes in the experimental groups $\mathrm{EG}_{1}, \mathrm{EG}_{2}$ and $\mathrm{EG}_{3}$ under the influence of the adsorbent inclusion was higher in comparison with the control animals by $0.660,0.133$ and $2.7710^{9} / 1$, respectively.

Was found that the total protein content in the blood of the experimental pigs of all groups at the end of the experience was significantly higher than at the beginning of the experience. Moreover, the highest content of total protein at the end of the experience was observed in CG $68.95 \%$, while in $\mathrm{EG}_{2}-64.43 \%, \mathrm{EG}_{1}-64.62 \%, \mathrm{EG}_{3}-$ $63.22 \%$ and the highest level of $\gamma$-globulin content was noted in $\mathrm{EG}_{1}$ and $\mathrm{EG}_{3}$, respectively, 9.33 and $9.53 \%$.

AST activity maximum increase (at a rate of 22.0-47.0 $\mathrm{u} / \mathrm{l})$ was observed in animals of the first experimental group by $11.11 \%$, and a decrease of $7.02 \%$ in the third experimental group relative to the control group. In the second experimental group, the AST index was within the normal range - $40.0 \mathrm{u} / 1$. ALT activity was reduced in comparison with the control group in the first experimental group by $4.23 \%-3.0$ units / 1 , in the second experimental group - by $19.72 \%$ - $14.0 \mathrm{u} / \mathrm{l}$.

In general, all blood parameters of the experimental animals did not exceed the physiological norms. This suggests that the adsorbent additive "Vitacorm REO-M" does not have an allergic or other negative effect on the animal's body and especially it helps to improve the mineral metabolism in it.

\section{ACKNOWLEDGEMENTS}

The authors would like to express their gratitude to the colleagues from Animal Science Department who served as their respondents for their significant suggestions and comments for the improvement of this study.

\section{REFERENCES}

[1] Wu F. Measuring the economic impacts of Fusarium toxins in animal feeds. Anim. Feed Sci. Tech. 2007, 137, 363-374.

[2] Mayra Carraro Di Gregorio, Diane Valganon de Neeff, Alessandra Vincenzi Jager, Carlos Humberto Corassin, Ágatha Cristina de Pinho Carão, Ricardo de Albuquerque, Antônio Carlos de Azevedo \&
Carlos Augusto Fernandes Oliveira. Mineral adsorbents for prevention of mycotoxins in animal feeds, Toxin Reviews, 2014, 33:3, 125-135. Available from: https://www.researchgate.net/ Mineral_adsorbents_for_prevention_of_mycotoxins_ in_animal_feeds [accessed Feb 24 2019].

[3] Jones FT, Genter MB, Hagler WM, Hansen JA, Mowrey BA, Poore MH, Whitlow LW. Understanding and coping with effects of mycotoxins in livestock feed and forage. North Carolina Agricultural Extension Service 523, 1994.

[4] Kim DH. A study of utilizability as feed additives for ground charcoal made of condensed sawdust on the broiler production. Graduate School of KonKuk University, 1990.

[5] Rabinovich MI Workshop on veterinary pharmacology and compounding: Tutorial. Moscow: Kolos, 2002. $240 \mathrm{p}$.

[6] Bikov O. Mycotoxins. Definition. Classification. Impact. Prevention methods. http://биомедиа.pф/nauka-i-praktika/tehnologii-iinnovacii/1152-mikotoksiny.html. [accessed 20.01.2014].

[7] Ivanov A. V. Mycotoxins - food security problem. http://soyanews.info/news/mikotoksiny - problema prodovolstvennoy_bezopasnosti.html In: Report of the International Veterinary Congress, Kazan, 2014 [accessed 25.11.2017].

[8] Papunidi K. X., Tremasov M. Ia., Semenov E. I. The problem of mycotoxicosis in pig breeding. In: 2 Symposium on pig breeding, Kazan, 2012. p. 17-21.

[9] Нассиф Аднан, Григорьев Д. Ю. Микотоксикозы в птицеводстве: проблемы и решения. http://www.tekro.ua/ru/statti/47-mikotoksikozy-vpticevodstve.html [accessed 15.01.2016].

[10] Kalashnikov A. P., Fisinin V. I., Sheglov V. V., Kleimenov N. N. The norms of feeding farm animals. Moscow, 2003. $455 \mathrm{p}$.

[11] Caisin L, HareaV. Methodology and technology research on feeding pigs. Chisinau, 2013, p. 168-177.

[12] Loza G. M., Udovenco E. A., Vovk V. E. Methods of determining the economic efficiency of agriculture the results of research and development work, new technologies, inventions and innovations. Moscow: «Kolos», 1980. $112 \mathrm{p}$.

[13] Grigoriev N. G. Some indicators of protein metabolism in heifers. In: Animal breeding, 1957, № 9, p. 44-46.

[14] Zavertaev B. P., Volgin V. I. Handbook of animal science breeder for dairy cattle breeding. Moscow: Kolos, 1984, p. 134-140.

[15] Kondrahin I. Alimentary and endocrine diseases of animals. Moscow: Agropromizdat, 1989. 256 p. 
[16] Caisin L., Carpincic V., Harea V., Bușev V., Bivol L.

A method for feeding pigs. In: International Specialized exhibition "INFOINVENT 2013". Chisinau, 2013, p. 141.

[17] Dejatkina S. V. Physiological rationale for the use of soybean okara and zeolite-containing marl in animal husbandry: Dissertation of the doctor of biological sciences: 03.03.01 and 06.02.08 / Dejatkina Svetlana, Ulianovsc, 2015. $321 \mathrm{p}$.

[18] Kocegarov S. N., Lilik S. N. and Pustovoi S. A. The effect of feeding iodized and selenium-enriched soy protein on the productivity of cattle and pigs. In: Animal husbandry, 2011, №3, p. 15-16.

[19] Poloziuk O. N. and Lapina T. I. Influence of conditions on the fattening and meat quality of animals. In: Agrarian Scientific Journal, 2015, №2, p. 26-29.

[20] Poloziuk O. N., Koshleak V. V. and Fediuk E. I. Assessment of the level of non-specific protection of the body of pigs of various interbreeding combinations during industrial crossing. In: Veterinary Pathology, 2012, №1, p. 144-147.

[21] Fediuk V. V., Krishtop E. A. and Baranikov A. I. Natural resistance of sows and their offspring. In: Modern technologies of agricultural production and priority areas for the development of agrarian science. Materials of the international scientificpractical conference. 4-7 february 2014, tom I, s. Persianovckii, 2014, p. 138 - 142.

[22] Fediuk V. V., Fediuk E. I. and Ilicenko D. V. Natural resistance and reproductive qualities of pigs in terms of industrial technology. In: Veterinary Pathology, 2005, № 1 (59), p. 134-142.

[23] Biochemical parameters of blood serum in various animal species. http://www.ld.ru/reviews/ilist4422.html [accessed 20.07.2018]. 